Proceedings

\title{
Beach contamination by marine litter: application of DPSIR (Driver, Pressure, State, Impact, Response) analysis
}

\author{
Ileana Federigi *, Marco Verani, Elena Balestri, Alberto Castelli, Davide De Battisti, Ferruccio Maltagliati, Virginia \\ Menicagli, Claudio Lardicci, Annalaura Carducci
}

Department of Biology, University of Pisa, Via S. Zeno 35/39, 56127 Pisa, Italy

* $\quad$ corresponding: ileana.federigi@biologia.unipi.it

\begin{abstract}
Marine litter, that is solid materials deliberately or accidentally released into marine and coastal environments, is a growing issue both at local and global scale. In particular, litter accumulation on beaches represents a relevant problem in touristic coastal areas. The DPSIR framework, already applied to tackle other environmental issues, can help in analysing the origin, impact, and possible solution of material stranded on the beach allowing a holistic approach in the "one health" perspective. It was applied in a popular sandy bathing location in the North-Western Tuscany (Italy). Information and data on origin and fate of beach-stranded material as well as existing local strategies were retrieved from a stakeholders' network. In summer 2020, a monitoring campaign was performed to evaluate the sanitary state of the shoreline and the impact of this material on coastal habitat. In a 7-year period (2014-2020), a mean amount of 1.548,3 tons of beach-stranded material have been collected and treated to separate sand (55\%), organic green fraction (31\%), and anthropogenic debris ( $2 \%$, while $12 \%$ weight-loss was attributable to evaporation. Analysis of historical environmental data revealed that shoreline accumulation of this material was associated with low atmospheric pressure, medium-strong winds, and storms. Preliminary monitoring data showed that the green fraction was mainly represented by wood and terrestrial plants with little quantity of the seagrass Posidonia oceanica, while most of the anthropogenic debris was rubber and metal. Microbial pollution of beached material was at least one order of magnitude higher than the surrounding environment (sand and seawater) for total coliforms, Escherichia coli, intestinal enterococci, and total fungal load. Overall, our results indicate a potential impact of beach-stranded material in this coastal area, with possible health risk for human population. The instruments already in place for the management of beached material, although consistent, could be further improved.
\end{abstract}

Keywords: Beach contamination; microbial pollution; DPSIR; marine litter

Publisher's Note: MDPI stays neu-

tral with regard to jurisdictional

claims in published maps and insti-

tutional affiliations.

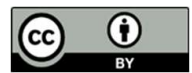

Copyright: (c) 2020 by the authors. Submitted for possible open access publication under the terms and conditions of the Creative Commons Attribution (CC BY) license (http://creativecommons.org/licenses /by/4.0/).

The 3rd International Electronic Conference on Environmental Research and Public Health 